\title{
Olfactory dysfunction in Alzheimer's disease Systematic review and meta-analysis
}

\author{
Maren de Moraes e Silva ${ }^{1}$, Pilar Bueno Siqueira Mercer ${ }^{1}$, \\ Maria Carolina Zavagna Witt' ${ }^{1}$ Renata Ramina Pessoa ${ }^{1}$
}

\begin{abstract}
Alzheimer's disease (AD), a neurodegenerative condition, is one of the most prevalent kinds of dementia, whose frequency doubles for every 5 years of age in elderly. Objective: To determine the correlation between $A D$ and olfactory alterations, identifying the most affected domains and exploring the utility of olfactory tests for complementing early diagnosis. Methods: Databases were searched using the terms "olfactory OR smell OR olfaction AND alzheimer" for articles related to the proposed theme. The selected studies were categorized and evaluated separately depending on the method of analysis of the olfactory tests: identification of odors, discrimination and recognition, and a metaanalysis was carried out. Results: Fifty-one articles were selected for analysis. The effect size for most studies was large, as were the summary values for each category of individualized olfactory analysis. Conclusion: Among the olfactory domains, except memory, identification appears to be the most altered in $A D$. The possibility of including tests that specifically evaluate the identification of odors as an item in early diagnostic evaluation should be explored. PROSPERO registration: CRD42018089076.
\end{abstract}

Key words: Alzheimer's disease, olfactory disorders, dementia, early diagnosis.

\section{ALTERAÇÕES OLFATÓRIAS EM DOENÇA DE ALZHEIMER: REVISÃo SISTEMÁTICA E META-ANÁLISE}

RESUMO. Neurodegenerativa, a doença de Alzheimer (DA) é um dos tipos mais prevalentes de demência, com frequência dobrando a cada 5 anos em idosos. Objetivo: Verificar a correlação entre DA e alterações olfatórias, identificando os domínios mais afetados e a possibilidade de utilização de testes olfatórios como complemento de diagnóstico precoce. Métodos: Bases de dados foram acessadas utilizando os termos "olfactory OR smell OR olfaction AND alzheimer" buscando artigos relacionados ao tema proposto. Os estudos selecionados foram categorizados e avaliados em separado a depender do método de análise olfatória: identificação de odores, discriminação e reconhecimento e uma meta-análise foi realizada. Resultados: Cinquenta e um artigos foram selecionado para análise. 0 tamanho do efeito da maioria dos estudos foi grande, assim como os valores sumários de cada categoria de análise olfatória. Conclusão: Entre os domínios olfatórios, excetuando memória, a identificação parece ser a mais alterada em DA. É possível explorar a possibilidade de adição de testes específico para avaliação de identificação de odores como um item na avaliação diagnóstica precoce. Registro PROSPERO: CRD42018089076.

Palavras-chave: doença de Alzheimer, transtornos do olfato, demência, diagnóstico precoce.

\begin{abstract}
$\triangle$ lzheimer's disease $(\mathrm{AD})$, a neurodegeneraAtive condition, is one of the most prevalent kinds of dementia, whose frequency doubles for every 5 years of age in elderly. ${ }^{1}$ Although the spectrum of the disease is more often related to cognitive disorders, it is necessary to pay attention to other factors
\end{abstract}

related to the process of illness for global analysis of the patient and, farther, as a means of seeking additional methods of early diagnosis. Currently, olfaction seems to be one of these factors. This basic sense is affected with normal aging, ${ }^{2}$ however, it seems to be even more intensely impaired in patients with

This study was conducted at Hospital da Cruz Vermelha Filial do Paraná. Neurology Department. Curitiba, PR, Brazil.

${ }^{1} M D$. Hospital da Cruz Vermelha Filial do Paraná. Neurology Department. Curitiba, PR, Brazil.

Maren de Moraes e Silva. Avenida Vicente Machado, 1310 - 80420-011 Curitiba PR - Brazil. E-mail: marenms@live.com

Disclosure: The authors report no conflicts of interest.

Received March 14, 2018. Accepted in final form May 07, 2018.

(cc) BY 
different neurodegenerative diseases, ${ }^{3}$ including AD, bearing in mind that olfaction is also correlated with recall mechanisms due to its synchronization with the hippocampus in the process of creation and retrieval of olfactory associative memory. ${ }^{4}$ In addition, a possible change in components of $\gamma$-secretase enzymes has been reported in previous studies as suggestive of olfactory alterations in patients with recent-onset $\mathrm{AD},{ }^{5}$ besides an influence of tau protein deposits in the olfactory bulb affecting the limbic system directly - a fact that was highly evident in $\mathrm{AD}$ and less frequently in healthy individuals. ${ }^{6}$ This highlights the importance of the study of these mechanisms to clarify the pathophysiology of degenerative diseases that affect the central nervous system.

A systematic review by Rahayel et al. ${ }^{7}$ previously evaluated the correlation between Alzheimer's disease and olfaction compared to Parkinson's disease, analyzing studies dated up to 2010, however, a lot of new material has been published addressing this topic in the last 8 years, calling for an updated analysis. The present study aimed to determine the correlation between $\mathrm{AD}$ and olfactory alterations, identifying the most affected domains and exploring the utility of olfactory tests for complementing early diagnosis.

\section{METHODS}

This is a systematic review and meta-analysis, registered on the PROSPERO database, under register CRD42018089076.

\section{Study eligibility}

Prior to the systematic search, a brief database search was carried out to identify possible key words to guide the review.

To search for articles to be included in the review, the databases MEDLINE - PubMed, SciELO and LILACS were used with the keywords "olfactory OR smell OR olfaction AND alzheimer". We selected studies investigating olfactory function in patients diagnosed with Alzheimer's disease compared to age-matched healthy controls. Inclusion criteria were articles in Portuguese and English, conducted in an adult population, and without publication date restriction. Cross-sectional and longitudinal, retrospective and prospective observational studies were included, whereas editorials, guidelines, letters and reviews were excluded. Exclusion criteria were also studies that did not describe the method used for diagnosing Alzheimer's disease, those that did not have a control group with age-matched individuals, and papers that did not provide the necessary information for performing the meta-analytical statistical analysis, even after contacting the respective authors, and whose values could not be calculated by us based on the data given in the articles. The literature search was concluded in 2018 February.

\section{Selection process}

The selection was initially done by reviewing titles and abstracts matching the inclusion criteria, together with an assessment based on the "PICO" strategy, providing initial screening of the potentially eligible studies. Based on this acronym-tool, "P" refers to "participants" (in our case, research in adult humans with Alzheimer's disease), "I" refers to "intervention" (olfactory alteration screening instruments), "C" for "comparison" (adult patients without dementia) and "O" to "outcomes" (correlation of olfactory impairment with the presence or absence of dementia). After the initial selection, the papers were read in full, excluding those that did not fit the study inclusion/exclusion criteria outlined previously. All of the processes described above were performed by two independent researchers. Disagreements were resolved by consensus. Finally, the kappa value was calculated as a means of evaluating the agreement level for the eligibility of the studies.

\section{Data analysis}

As a way of standardizing the results of the analyzed tests, Cohen's $\mathrm{D}^{9}$ was used to calculate effect size. Results $<0.2$ were considered as a low effect, $>0.5$ as medium and $\geq 0.8$ as having a large effect.

The homogeneity of the included studies was analyzed by Cochran $\mathrm{Q}^{10}$ and $\mathrm{I}^{2}$ statistics. In cases presented as heterogeneous, the data were reassessed using metaregression techniques and by subgroup analysis, when appropriate. Continuous variables were analyzed by the Mann Whitney test and Pearson's correlation test. The Kruskal Wallis test was also used to compare the three groups.

Statistical analysis was performed using $\mathrm{R}^{11}$ software and forest plots were generated by "DistillerSR Forest Plot Generator tool from Evidence Partners", available online. ${ }^{12}$ Necessary information for statistical analysis that was not explicit in the article itself was calculated based on published data and, when not possible to be obtained in any other way, were requested from the authors by electronic mail.

The publication bias was assessed by creating a funnel plot for subsequent analysis according to Duval and Tweedie ("trim and fill") ${ }^{13}$ and Roshental ("Fail safe N") methods. ${ }^{14}$ 


\section{Study categorization}

The selected studies were categorized and evaluated separately depending on the method of analysis of the olfactory tests: identification of odors, discrimination and recognition. Identification is understood here as the ability to name the smell, while discrimination refers to the ability to detect specific olfactory stimulus or evaluation of the olfactory threshold in a series of tests, and "recognition" means the study of olfactory memory.

Articles that analyzed more than one of these domains underwent separate statistical analysis, according to their categorization.

\section{RESULTS}

\section{Eligible study selection}

The search of the literature using the key terms retrieved a total of 1234 articles. Of these, 1144 were excluded after the initial review of titles and abstracts. Of the remaining articles, 28 were excluded after applying the PICO criteria and, after access to the full text, 11 articles were withdrawn. This selection sequence is depicted in figure 1 along with the reasons for exclusions. Authors' concordance was calculated with a kappa of 0.95.

\section{Characteristics of selected studies}

The selected studies encompassed papers published over the last 32 years: the oldest from 1986 and the

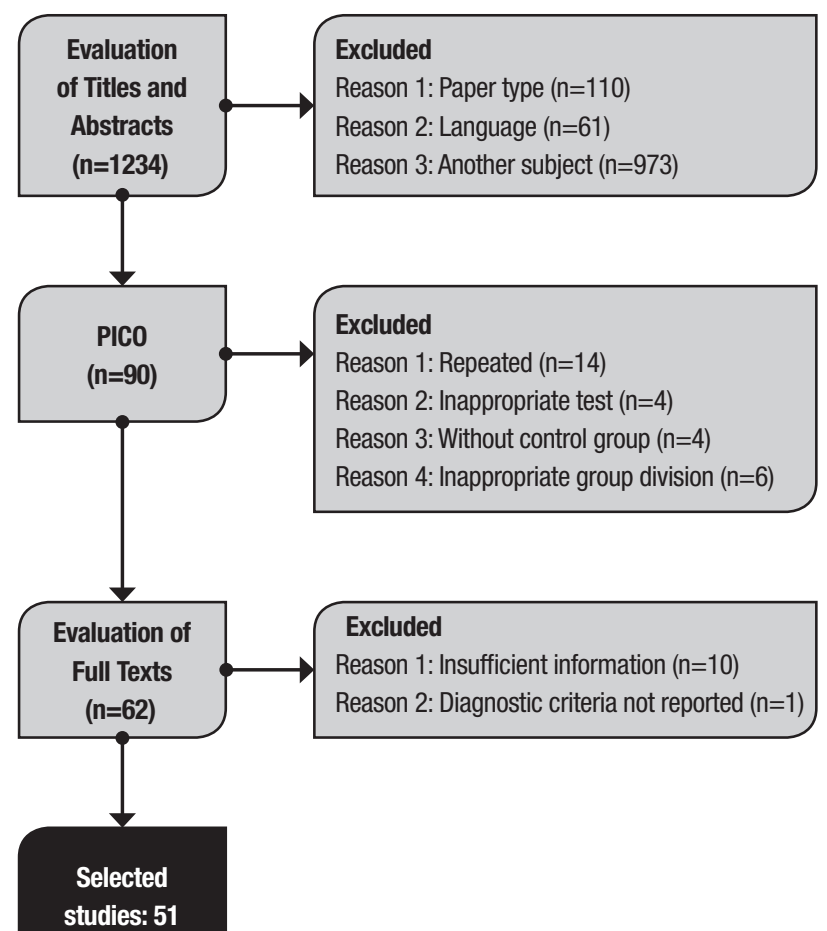

Figure 1. Study selection flowchart. most recent dating to 2017. Most of these studies were from the United States of America, followed by European countries in conjunction. No studies published by South American or African countries were found.

In relation to categorical stratification, the identification of odors was measured 40 times, ${ }^{15-52}$ discrimination 21 times $^{16,21,22,26,29,34,35,37,38,46,53-61}$ and recognition only 6 times, ${ }^{17,18,40,57,62,63}$ representing samples of 3328, 1062 and 244 evaluated individuals, respectively.

Individual characteristics of selected articles are given in Table 1.

\section{Olfactory evaluation tools}

Eleven tools for assessing olfactory ability were evaluated (with all "homegrown" instruments considered as only 1 type, regardless of the particularity of each). The most commonly used included the University of Pennsylvania Smell Identification Test (UPSIT) and the Sniffin' Sticks Odor Identification Test (SSOIT).

The UPSIT tool (produced by Sensonics Inc., Haddon Heights, NJ) consists of 40 types of odors associated with multiple choice questions. Some studies included in the present review used this scale partially as a means of testing the applicability of a faster scale.

The SSOIT test entails presenting only 16 odors to the patient, who also answers multiple-choice questions with 4 items each.

\section{Demographic characteristics}

The mean age of the patients evaluated in the Alzheimer's disease groups for identification tests was 73.52 years (95\%CI 72.32-74.72, SD 3.81), ranging from 64.2 to 81.9 years old, whereas the control group had a mean age of 70.85 years (95\%CI 68.68-73.02, SD 6.88), ranging from 63.4 to 79.6 years. For the same category, the gender ratio was predominantly female, with a 1.4:1 proportion. The correlations between age and sex predominance in relation to olfactory performance were not statistically significant ( $0.004 \mathrm{p} 0.98$ and $\mathrm{Z}-0.27$ p 0.79 , respectively).

The mean Mini-Mental State Examination (MMSE) score was 21.61 (95\%CI 20.89-22.33, SD 1.96), with a mean educational level of 11.94 years of study (95\%CI 11.07-12.81, SD 2.06) among the identification studies. All articles evaluated individuals with an average of 9 or more years of education, with only the paper by Chan et al. ${ }^{24}$ below this level, with an average of 5 years. The correlation between MMSE performance and olfactory tests was not statistically significant $(R-0.35$, p 0.059). 
Table 1. Study characteristics.

\begin{tabular}{|c|c|c|c|c|}
\hline Author (Year) & Country & Modality & Tool & Criteria \\
\hline Warner, et al (1986) & USA & Identification & UPSIT-40 & DSM III \\
\hline Rezek, et al (1987) & USA & Identification & Homegrown & Berg et al \\
\hline Moberg, et al (1987) & USA & Recognition & Homegrown & DSM III \\
\hline Kesslak, et al (1988) [a] & USA & Identification & UPSIT-40 & NINCDS-ADRDA \\
\hline Kesslak, et al (1988) [b] & USA & Recognition & UPSIT-40 & NINCDS-ADRDA \\
\hline Kesslak, et al (1991) [a] & USA & Identification & UPSIT-40 & NINCDS-ADRDA \\
\hline Kesslak, et al (1991) [b] & USA & Recognition & UPSIT-40 & NINCDS-ADRDA \\
\hline Serby, et al (1991) & USA & Identification & UPSIT-40 & NINCDS-ADRDA \\
\hline Buchsbaum, et al (1991) & USA & Recognition & Match-to-sample test & NINCDS-ADRDA \\
\hline Nordin, et al (1995) & USA & Discrimination & Homegrown & NINCDS-ADRDA and DSM III-R \\
\hline Moberg, et al (1997) & USA & Identification & UPSIT-40 & NINCDS-ADRDA \\
\hline Larsson, et al (1999) [a] & Sweden & Identification & Homegrown & NINCDS-ADRDA \\
\hline Larsson, et al (1999) [b] & Sweden & Discrimination & Homegrown & NINCDS-ADRDA \\
\hline Kareken, et al (2001) [a] & USA & Identification & UPSIT-40 & NINCDS-ADRDA \\
\hline Kareken, et al (2001) [b] & USA & Discrimination & Homegrown & NINCDS-ADRDA \\
\hline Royet, et al (2001) & France & Identification & Homegrown & NINCDS-ADRDA \\
\hline Chan, et al (2002) & China & Identification & Homegrown & DSM IV \\
\hline Duff, et al (2002) & USA & Identification & PST & DSM IV \\
\hline Peters, et al (2003) [a] & Germany & Identification & SS-0IT & NINCDS-ADRDA \\
\hline Peters, et al (2003) [b] & Germany & Discrimination & SS-OIT & NINCDS-ADRDA \\
\hline Getchell, et al (2003) & USA & Discrimination & Homegrown & NINCDS-ADRDA \\
\hline Suzuki, et al (2004) & Japan & Identification & CC-SIT & DSM IV and NINCDS-ADRDA \\
\hline Gilbert, et al (2004-1) [a] & USA & Discrimination & Homegrown & NIA, CERAD, DSM III and NINCDS-ADRDA \\
\hline Gilbert, et al (2004-1) [b] & USA & Recognition & Homegrown & NIA, CERAD, DSMIII and NINCDS-ADRDA \\
\hline Gilbert, et al (2004-2) & USA & Discrimination & Homegrown & NIA and CERAD \\
\hline Tabert, et al (2005) [a] & USA & Identification & UPSIT-40 & DSM IV \\
\hline Tabert, et al (2005) [b] & USA & Identification & B-SIT & DSM IV \\
\hline Tabert, et al (2005) [c] & USA & Identification & 10-item Scale & DSM IV \\
\hline Djordjevic, et al (2006) [a] & Canada & Identification & UPSIT-40 & NINCDS-ADRDA \\
\hline Djordjevic, et al (2006) [b] & Canada & Discrimination & Homegrown & NINCDS-ADRDA \\
\hline Kjelvik, et al (2007) & Norway & Identification & B-SIT & NINCDS-ADRDA \\
\hline Pentzek, et al (2007) & Germany & Identification & SS-0IT & NINCDS-ADRDA \\
\hline
\end{tabular}


Table 1. Study characteristics (continuation).

\begin{tabular}{|c|c|c|c|c|}
\hline Author (Year) & Country & Modality & Tool & Criteria \\
\hline McLaughlin, et al (2007) & USA & Identification & B-SIT & NINCDS-ADRDA \\
\hline Sundermann, et al (2007) & USA & Discrimination & Homegrown & NINCDS-ADRDA and DSM III - $R$ \\
\hline Jungwirth, et al (2009) & Austria & Identification & PST & NINCDS-ADRDA \\
\hline Steinbach, et al (2009) & Germany & Identification & SS-OIT & NINCDS-ADRDA \\
\hline Williams, et al (2009) [a] & United Kingdom & Identification & SS-OIT & NINCDS-ADRDA \\
\hline Williams, et al (2009) [b] & United Kingdom & Discrimination & SS-OIT & NINCDS-ADRDA \\
\hline Steinbach, et al (2009) & Germany & Discrimination & SS-OIT & NINCDS-ADRDA \\
\hline Förster, et al (2010) & Germany & Identification & SS-OIT & NINCDS-ADRDA \\
\hline Li, et al (2010) [a] & USA & Identification & UPSIT-40 & NINCDS-ADRDA \\
\hline Li, et al (2010) [b] & USA & Discrimination & UPSIT-40 & NINCDS-ADRDA \\
\hline Razani, et al (2010) & USA & Identification & Homegrown & NINCDS-ADRDA and DSM III-R \\
\hline Wang, et al (2010) & USA & Identification & UPSIT-40 & NINCDS-ADRDA \\
\hline Bahar-Fuchs, et al (2010) [a] & Australia & Identification & UPSIT-10 & NINCDS-ADRDA \\
\hline Bahar-Fuchs, et al (2010) [b] & Australia & Recognition & Homegrown & NINCDS-ADRDA \\
\hline Razani, et al (2010) & USA & Discrimination & Homegrown & NINCDS-ADRDA and DSM III-R \\
\hline Bahar-Fuchs, et al (2011) & Australia & Identification & UPSIT-6 & NINCDS-ADRDA \\
\hline Makowska, et al (2011) & Poland & Identification & PST & NINCDS-ADRDA \\
\hline Schofield, et al (2012) & Australia & Identification & UPSIT-20 & DSM IV and NINCDS-ADRDA \\
\hline Velayudhan, et al (2013) & United Kingdom & Identification & UPSIT-40 & NINCDS-ADRDA \\
\hline Seligman, et al (2013) & USA & Identification & SS-OIT & CERAD \\
\hline Servello, et al (2015) [a] & Italy & Identification & SSET & NINCDS-ADRDA \\
\hline Servello, et al (2015) [b] & Italy & Discrimination & SSET & NINCDS-ADRDA \\
\hline Velayudhan, et al (2015) & United Kingdom & Identification & UPSIT-40 & NINCDS-ADRDA \\
\hline Hori, et al (2015) & Japan & Discrimination & Homegrown & NINCDS-ADRDA and DSM IV \\
\hline Vyhnalek, et al (2015) & Czech Republic & Discrimination & MHST & NINCDS-ADRDA and DSM IV \\
\hline Hagemeier, et al (2016) & USA & Identification & UPSIT-40 & NINCDS-ADRDA \\
\hline Passler, et al (2016) & USA & Identification & UPSIT-40 & ICD-9-CM \\
\hline Reijs, et al (2017) & Europe & Identification & B-SIT & NINCDS-ADRDA \\
\hline Christensen, et al (2017) & Denmark & Identification & PST & Gauthier, 2006 \\
\hline Quarmley, et al (2017) & USA & Identification & SS-0IT & CERAD \\
\hline
\end{tabular}

UPSIT-40: University of Pennsylvania Smell Identification 40 items; DSM III: Diagnostic and Statistical Manual of Mental Disorders III Edition; NINCDS-ADRDA: National Institute of Neurological and Communicative Disorders and Stroke - Alzheimer's Disease and Related Disorders Association; DSM III-R: Diagnostic and Statistical Manual of Mental Disorders III Edition Revised; DSM IV: Diagnostic and Statistical Manual of Mental Disorders IV Edition; PST: Pocket Smell Test; SS-OIT: Sniffin' Sticks Odor Identification Test; CC-SIT: Cross Cultural Smell Identification Test; NIA: National Institute on Aging; CERAD: Consortium to Establish a Registry for Alzheimer's Disease; B-SIT: Brief Smell Identification Test; UPSIT-10: University of Pennsylvania Smell Identification 10 items; UPSIT-6: University of Pennsylvania Smell Identification 6 items; UPSIT-20: University of Pennsylvania Smell Identification 20 items; SSET: Sniffin' Sticks Extended Test; MHST: Motol Hospital Smell Test. 


\section{Effect size and group comparison}

The effect size for most studies was large, as were the summary values for each category of individualized olfactory analysis. For identification, the value of $\mathrm{d}$ ranged from 0.37 to 5.65 (mean 1.99 , 95\% CI 1.591.66), for discrimination from 0.28 to 2.76 (mean 0.81 , $95 \%$ CI $0.77-0.85$ ), and recognition from 0.38 to 8.33 (mean 3.13, 95\% CI 1.15-1.86).

All categories were heterogeneous in analysis, with $Q$ values of 253.25 (I $\mathrm{I}^{2}$ 97\%), 317.18 (I $\mathrm{I}^{2}$ 93\%) and $1729\left(\mathrm{I}^{2}\right.$ 97\%) for recognition, discrimination and identification, respectively (Figures 2 and 3 ).

The difference between the three olfactory domains was statistically significant (H 14.51 df 2 p <0.001), with the difference between identification and discrimination being more intensely significant (Z 3.65 p <0.001). There were too few studies addressing recognition for accurate statistical analysis in terms of comparison.

Statistical differences between the UPSIT (mean $\mathrm{d}$ 1.18) and SSOIT (mean d 1.6) tests were also analyzed separately, with a statistically significant relationship (Z 2.48 p 0.012).

\section{Moderator analysis}

The evaluation of the possible factors of heterogeneity through meta-regression revealed that heterogeneity was maintained despite the use of moderators: MMSE $(\mathrm{k}=30 \mathrm{p}=0.59 \mathrm{Z}=-0.53)$. age $\mathrm{k}=40 \mathrm{p}=0.98 \mathrm{Z}=-0.02)$.

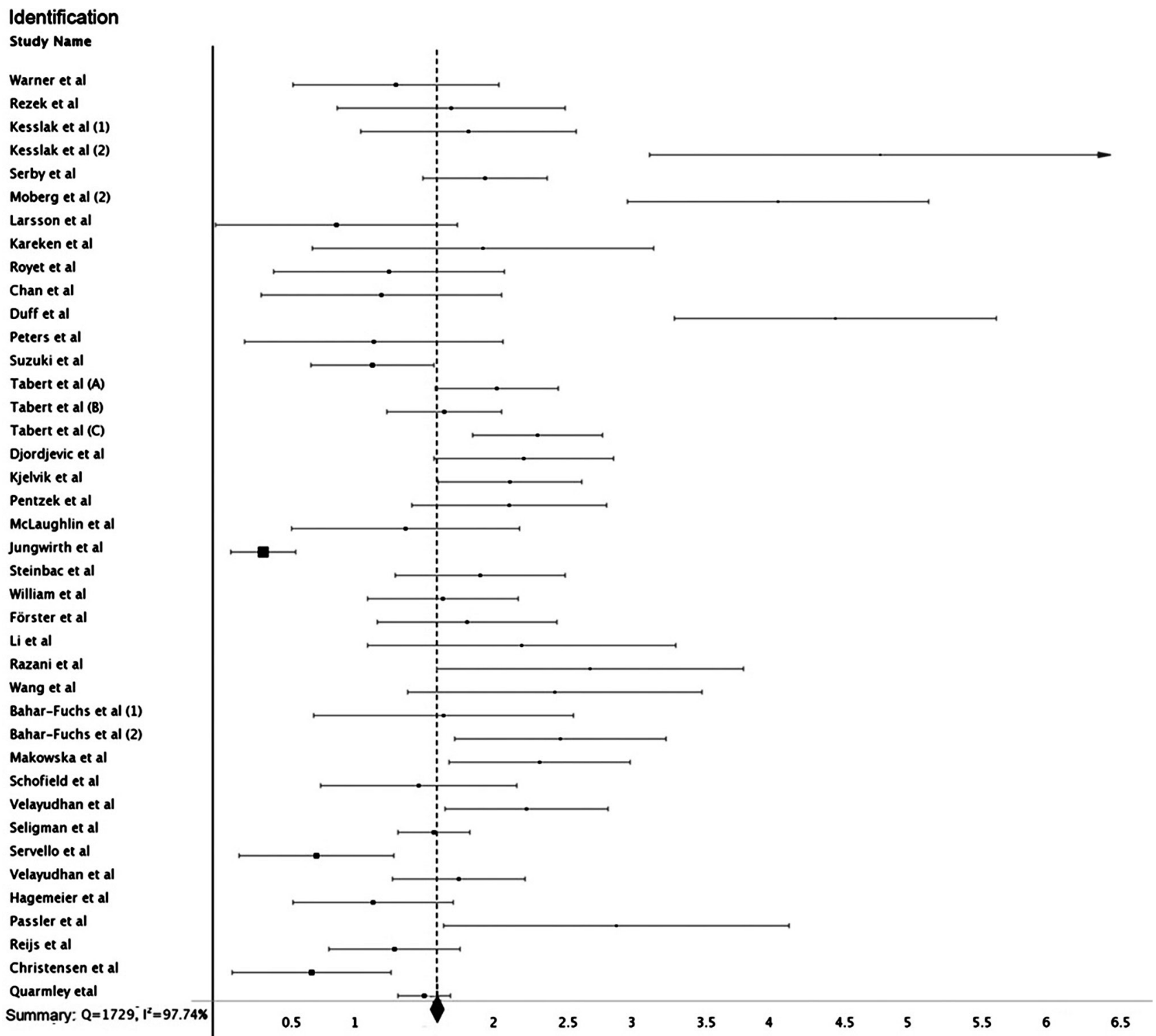

Figure 2. Individual study effect sizes: identification domain. 
sample size $(\mathrm{k}=40 \mathrm{p}=0.61 \mathrm{Z}=-0.50)$ and gender $(\mathrm{k}=37$ $\mathrm{p}=0.90 \mathrm{Z}=0.12$ ).

Analysis in relation to smoking could not be performed due to insufficient information: only 9 studies $^{19,22,26,27,36,42,44,46,47}$ employed this item as an exclusion criterion and only 5 articles ${ }^{20,21,25,29,34}$ reported the number of smokers present in the sample. The same situation occurred for onset and duration of symptoms of $\mathrm{AD}$, with insufficient data available. Most studies defined history of prior brain injury as an exclusion criteria. However, when the studies that did not take this criteria into account or did not report this detail were removed, the heterogeneity was maintained $(\mathrm{k}=30$, $\mathrm{p}<0.0001, \mathrm{z}-11.58)$.

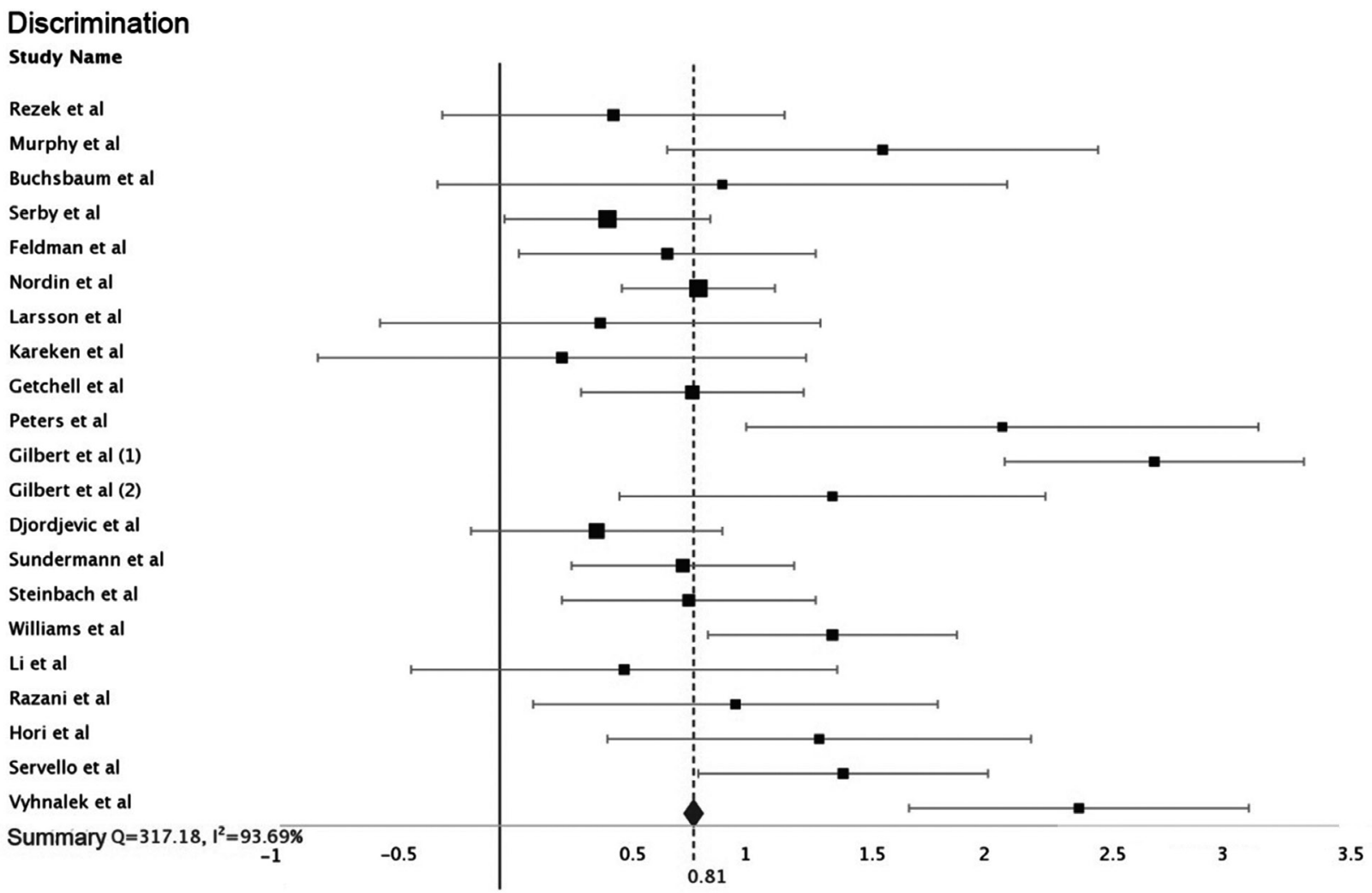

Recognition

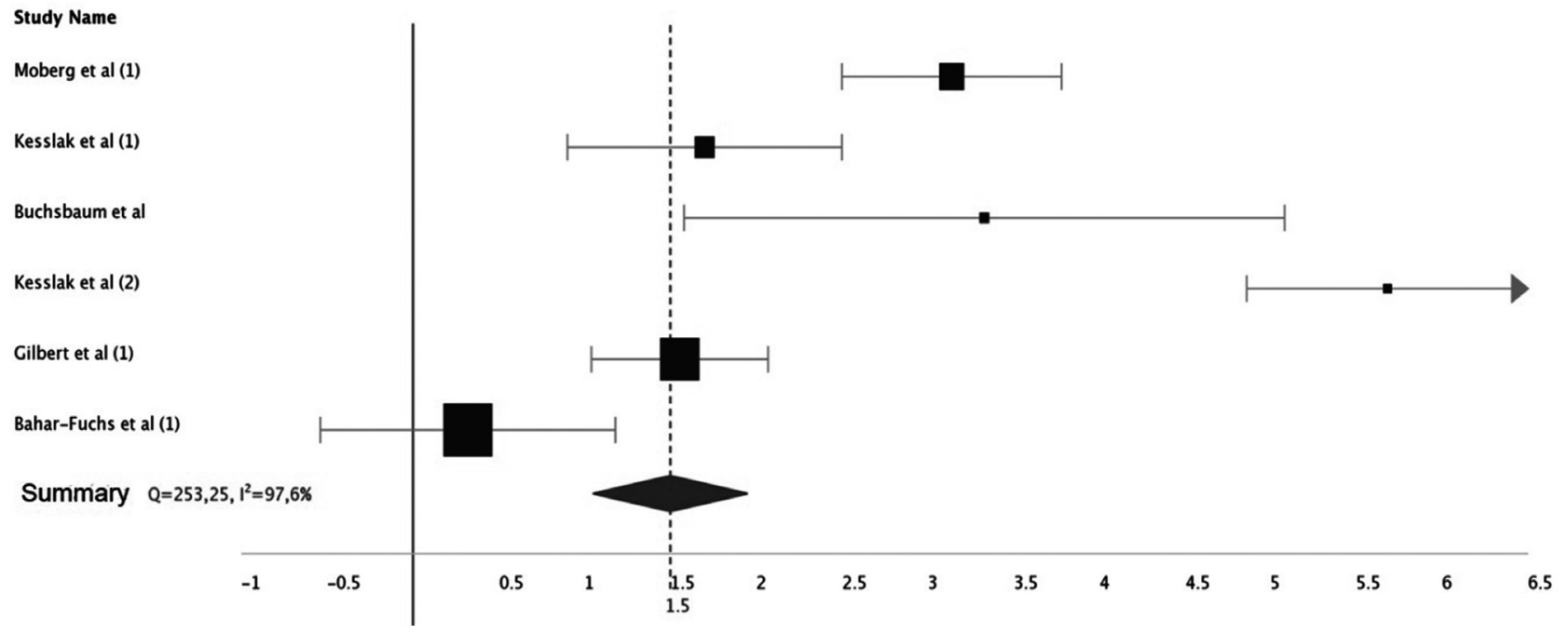

Figure 3. Individual study effect sizes: discrimination and recognition domains. 
Regarding the type of tool for evaluation, a subgroup analysis was carried out based on the categories UPSIT, SSOIT and "others": the heterogeneity between the studies persisted. Analysis by diagnostic criteria subgroups also maintained heterogeneity.

\section{Publication bias}

Visual analysis of the funnel plot showed asymmetry. Subsequently, the application of Duval and Tweedie ${ }^{13}$ method revealed the need for 21 studies on the right side to ensure symmetry. However, the analysis using the Roshental approach ${ }^{14}$ revealed that 18347729 "null" studies would need to be incorporated into the present review to negate the effect observed here $(\mathrm{p}<0.001)$.

\section{DISCUSSION}

Correlation between olfactory changes and neurodegenerative diseases has been extensively analyzed in current medical literature. The present meta-analysis aimed to specifically evaluate these alterations in Alzheimer's disease, which is associated with impairment both in terms of identification and discrimination of odors, as well as recognition. This fact was corroborated by the present study, which found a large effect size. These findings are in agreement with previous analyses of a smaller number of studies, ${ }^{7}$ including in the case of early diagnosis, and are in line with a previous meta-analysis of these alterations in mild cognitive impairment. ${ }^{64}$

Among the olfactory domains, except memory, identification appears to be the most altered in $\mathrm{AD}$, in agreement with previous studies. ${ }^{7}$ It is also necessary to take into account the fact that, even in healthy elderly groups there is a reduction in olfactory sensitivity. ${ }^{2}$ However, domains are affected differently in relation to Alzheimer's disease, as can be verified in analyses demonstrating that in the healthy elderly population discrimination (olfactory thresholds) is the most affected. ${ }^{2}$ These differences can be explained by the association of execution and memory cognitive domains, related in part to performance on tests that involve identification and recognition, being closely related with semantic memory $^{65}$ - factors which should be taken into account when choosing the best test for olfactory evaluation.

On the other hand, differences in relation to gender proportion of samples among the elderly population can be expected, since women have higher life expectancies. ${ }^{66}$ However, the present study failed to find a statistical difference between the genders. By contrast, a previous study by Roalf et al. ${ }^{64}$ involving a cognitive impairment analysis, found a significant difference between genders, showing greater involvement in men.
An additional point to be analyzed and which required separate evaluations, were the changes in the current diagnostic criteria, considering that the analyzed studies were published over a 30-year period and that the diagnostic criteria used may have differed. ${ }^{67,68}$ However, these modifications do not appear to have had a substantial impact on the results when a metaregression was performed.

Regarding correlation between MMSE score and olfactory evaluation, it is surprising that no statistically significant difference was found. This is possibly due to the small sample size adopted by many of the studies included in this review, which may have greatly impaired the analysis. In view of the previously explained relationship between certain types of olfactory assessment and cognitive issues, a significant difference could be expected between the disease and control groups. However, this finding is in agreement with previous studies evaluating pre-morbid conditions.${ }^{64}$ Conversely, an observational study found a correlation between low score in cognitive screening and larger olfactory sensory deficits. ${ }^{40}$ Given this evidence, it is prudent that in dementia, the actual sensory alteration measured by the tests is differentiated from cognitive alterations, for adequate analysis of predictive value for initial disease and/or worse outcome. An alternative hypothesis for non-correlation may be the fact that the MMSE provides only a superficial study, requiring a complete and extensive neuropsychological evaluation to differentiate the origin of the observed deficits.

Several types of tests for distinguishing olfactory deficits can be used, while many studies have devised their own tests, demonstrating their ease of execution. On the other hand, this heterogeneity of methods can hamper global statistical analysis. The most commonly used commercial tests include UPSIT and SSOIT, with a statistically significant difference between them in the present study. Results indicated a greater effect for the SS-OIT, possibly due to the shorter application time, requiring less effort for the patient. When using both tests, we are again facing the question of cognitivesensory differentiation, since both use forced multiplechoice questions. The use of other types of tools and approaches can help elucidate and differentiate the aspects affected by the disease.

This review is limited in relation to the risk of publication bias, as explained in the results. In addition, it is important to mention that the vast majority of the studies that addressed the application of the tests had samples containing individuals with medium-to-high education from developed countries. Therefore, care 
should be taken when generalizing these results to populations with different educational levels and cultural backgrounds.

The presence of greater olfactory involvement in patients with $\mathrm{AD}$ is clear, and the possibility of including tests that specifically evaluate the identification of odors as an item in early diagnostic evaluation, and maybe prognosis, together with a detailed cognitive evaluation, should be explored.

Further studies are needed to evaluate this applicability in other populations, taking a more homogeneous methodological approach in terms of gender distribu- tion and assessing confounding factors such as previous smoking.

Author contributions. Maren de Moraes e Silva: study concept and design, literature search, drafting and revising the manuscript, analysis and interpretation of data, statistical analysis. Pilar Bueno Siqueira Mercer: literature search, analysis and interpretation of data, revising the manuscript. Maria Carolina Zavagna Witt: analysis and interpretation of data, revising the manuscript. Renata Ramina Pessoa: analysis and interpretation of data, revising the manuscript.

\section{REFERENCES}

1. Snowdon D, Greiner LH, Mortimer JA, Riley KP, Greiner PA, Markesbery WR. Brain infarction and the clinical expression of Alzheimer disease -The Nun Study. JAMA 1997;227:813-7.

2. Doty $R L$, Kamath $V$. The influences of age on olfaction: a review. Front Psychol 2014;5:1-20.

3. Doty RL, Perl DP, Steele JC, Chen KM, Pierce JD Jr, Reyes P, et al. Odor identification deficit of the parkinsonism-dementia complex of Guam: equivalence to that of Alzheimer's and idiopathic Parkinson's disease. Neurology. 1991;41(2):77-80.

4. Igarashi KM, Lu L, Colgin LL, Moser MB, Moser El. Coordination of entorhinal-hippocampal ensemble activity during associative learning. Nature. 2014;510:143-147

5. Kim JY, Rasheed A, Yoo SJ, Kim SY, Cho B, Son G, et al. Distinct amyloid precursor protein processing machineries of the olfactory system. Biochem Biophys Res Commun. 2018;495(1):533-8.

6. Attems J, Lintner F, Jellinger KA. Olfactory involvement in aging and Alzheimer's disease: an autopsy study. J Alzheimers Dis. 2005;7(2): 149-57.

7. Rahayel S, Frasnelli J, Joubert S. The effect of Alzheimer's disease and Parkinson's disease on olfaction: a meta-analysis. Behav Brain Res. 2012;231(1):60-74.

8. Santos CMC, Pimenta CAM, Nobre MRC. A estratégia PICO para a construção da pergunta de pesquisa e busca de evidências. Rev Latinoam Enfermagem. 2007;15(3):508-11

9. Cohen J, Cohen P. Applied multiple regression/correlation analysis for the behavioral sciences. 2nd ed. Hillsdale, N.J: L. Erlbaum, 1983.

10. Cochran WG. The comparison of percentages in matched samples. Biometrika. 1950;37(3-4):256-66.

11. R Core Team, R: A Language and Environment for Statistical Computing, R Foundation for Statistical Comput-ing, Vienna, Austria (2016). Disponível em: https://www.R-project.org/

12. DistillerSR Forest Plot Generator from Evidence Partners. Disponível em: https://www.evidencepartners.com/

13. Duval S, Tweedie R. Trim and fill: a simple funnel-plot-based method of testing and adjusting for publication bias in meta-analysis. Biometrics 2000;56:455-63.

14. Rosenthal, R. The file drawer problem and tolerance for null results. Psychological Bulletin. 1979;86(3):638-64.

15. Warner MD, Peabody CA, Flattery JJ, Tinklenberg JR. Olfactory deficits and Alzheimer's disease. Biol Psychiatry. 1986;21(1):116-8.

16. Rezek DL. Olfactory deficits as a neurologic sign in dementia of the Alzheimer type. Arch Neurol. 1987;44(10):1030-2.

17. Kesslak JP, Cotman CW, Chui HC, Van den Noort S, Fang H, Pfeffer R, et al. Olfactory tests as possible probes for detecting and monitoring Alzheimer's disease. Neurobiol Aging. 1988;9(4):399-403.

18. Kesslak JP, Nalcioglu O, Cotman CW. Quantification of magnetic resonance scans for hippocampal and parahippocampal atrophy in Alzheimer's disease. Neurology. 1991;41(1):51-4.

19. Serby $M$, Larson $P$, Kalkstein $D$. The nature and course of olfactory deficits in Alzheimer's disease. Am J Psychiatry. 1991;148(3):357-60.

20. Moberg PJ, Doty RL, Mahr RN, Mesholam RI, Arnold SE, Turetsky BI, et al. Olfactory identification in elderly schizophrenia and Alzheimer's disease. Neurobiol Aging. 1997;18(2):163-7.
21. Larsson M, Semb H, Winblad B, Amberla K, Wahlund LO, Bäckman L. Odor identification in normal aging and early Alzheimer's disease: effects of retrieval support. Neuropsychology. 1999;13(1):47-53.

22. Kareken DA, Doty RL, Moberg PJ, Mosnik D, Chen SH, Farlow MR, et al. Olfactory-evoked regional cerebral blood flow in Alzheimer's disease. Neuropsychology. 2001;15(1):18-29.

23. Royet JP1, Croisile B, Williamson-Vasta R. Rating of different olfactory judgements in Alzheimer's disease. Chem Senses. 2001;26(4):409-17.

24. Chan A, Tam J, Murphy C, Chiu H, Lam L. Utility of olfactory identification test for diagnosing Chinese patients with Alzheimer's disease. J Clin Exp Neuropsychol. 2002;24(2):251-9.

25. Duff K, McCaffrey RJ, Solomon GS. The Pocket Smell Test: successfully discriminating probable Alzheimer's dementia from vascular dementia and major depression. J Neuropsychiatry Clin Neurosci. 2002; 14(2):197-201.

26. Peters JM, Hummel T, Kratzsch T, Lötsch J, Skarke C, Frölich L. Olfactory function in mild cognitive impairment and Alzheimer's disease: an investigation using psychophysical and electrophysiological techniques. Am J Psychiatry. 2003;160(11):1995-2002.

27. Suzuki Y, Yamamoto S, Umegaki H, Onishi J, Mogi N, Fujishiro H, et al. Smell identification test as an indicator for cognitive impairment in Alzheimer's disease. Int J Geriatr Psychiatry. 2004;19(8):727-33.

28. Tabert MH, Liu X, Doty RL, Serby M, Zamora D, Pelton GH, et al. A 10 -item smell identification scale related to risk for Alzheimer's disease. Ann Neurol. 2005;58(1):155-60.

29. Djordjevic J, Jones-Gotman M, De Sousa K, Chertkow H. Olfaction in patients with mild cognitive impairment and Alzheimer's disease. Neurobiol Aging. 2008;29(5):693-706

30. Kjelvik G, Sando SB, Aasly J, Engedal KA, White LR. Use of the Brief Smell Identification Test for olfactory deficit in a Norwegian population with Alzheimer's disease. Int J Geriatr Psychiatry. 2007;22(10):1020-4.

31. Pentzek M, Grass-Kapanke B, Ihl R. Odor identification in Alzheimer's disease and depression. Aging Clin Exp Res. 2007;19(3):255-8.

32. McLaughlin NC, Westervelt HJ. Odor identification deficits in frontotemporal dementia: a preliminary study. Arch Clin Neuropsychol. 2008;23(1): 119-23.

33. Jungwirth S, Zehetmayer S, Bauer P, Weissgram S, Tragl KH, Fischer P. Screening for Alzheimer's dementia at age 78 with short psychometric instruments. Int Psychogeriatr. 2009;21(3):548-59.

34. Steinbach S, Hundt W, Vaitl A, Heinrich P, Förster S, Bürger K, et al. Taste in mild cognitive impairment and Alzheimer's disease. J Neurol. 2010;257(2):238-46.

35. Williams SS, Williams J, Combrinck M, Christie S, Smith AD, McShane $\mathrm{R}$. Olfactory impairment is more marked in patients with mild dementia with Lewy bodies than those with mild Alzheimer disease. J Neurol Neurosurg Psychiatry. 2009;80(6):667-70.

36. Förster S, Vaitl A, Teipel SJ, Yakushev I, Mustafa M, la Fougère C, et al. Functional representation of olfactory impairment in early Alzheimer's disease. J Alzheimers Dis. 2010;22(2):581-91.

37. Li W, Howard JD, Gottfried JA. Disruption of odour quality coding in piriform cortex mediates olfactory deficits in Alzheimer's disease. Brain. 2010;133(9):2714-26. 
38. Razani J, Chan A, Nordin S, Murphy C. Semantic networks for odors and colors in Alzheimer's disease. Neuropsychology. 2010;24(3):291-9.

39. Wang, J, Eslinger, PJ, Doty, RL, Zimmerman, EK, Grunfeld, R, Sun, X, et al. Olfactory deficit detected by $\mathrm{fMRl}$ in early Alzheimer's disease. Brain Res. 2010;1357:184-94.

40. Bahar-Fuchs A, Moss S, Rowe C, Savage G. Olfactory performance in $\mathrm{AD}, \mathrm{aMCl}$, and healthy ageing: a unirhinal approach. Chem Senses. 2010;35(9):855-62.

41. Bahar-Fuchs A, Moss S, Rowe C, Savage G. Awareness of olfactory deficits in healthy aging, amnestic mild cognitive impairment and Alzheimer's disease. Int Psychogeriatr. 2011;23(7):1097-106.

42. Makowska I, Kloszewska I, Grabowska A, Szatkowska I, Rymarczyk K. Olfactory deficits in normal aging and Alzheimer's disease in the polish elderly population. Arch Clin Neuropsychol. 2011;26(3):270-9.

43. Schofield PW, Ebrahimi H, Jones AL, Ateman GA, Murray SR. An olfactory 'stress test' may detect preclinical Alzheimer's disease. 2012; 12(24):1-8

44. Velayudhan L, Pritchard M, Powell JF, Proitsi P, Lovestone S. Smell identification function as a severity and progression marker in Alzheimer's disease. Int Psychogeriatr. 2013;25(7):1157-66.

45. Seligman SC, Kamath V, Giovannetti T, Arnold SE, Moberg PJ. Olfaction and apathy in Alzheimer's disease, mild cognitive impairment, and healthy older adults. Aging Ment Health. 2013;17(5):564-70.

46. Servello A, Fioretti A, Gualdi G, Di Biasi C, Pittalis A, Sollaku S, et al. Olfactory Dysfunction, Olfactory Bulb Volume and Alzheimer's Disease: Is There a Correlation? A Pilot Study. J Alzheimers Dis. 2015;48(2):395-402.

47. Velayudhan L, Gasper A, Pritchard M, Baillon S, Messer C, Proitsi P. Pattern of Smell Identification Impairment in Alzheimer's Disease. J Alzheimers Dis. 2015;46(2):381-7.

48. Hagemeier J, Woodward MR, Rafique UA, Amrutkar CV, Bergsland N, Dwyer MG, et al. Odor identification deficit in mild cognitive impairment and Alzheimer's disease is associated with hippocampal and deep gray matter atrophy. Psychiatry Res. 2016;255:87-93.

49. Passler JS, Doty RL, Dolske MC, St Louis PG, Basignani C, Pepe JW, et al. Olfactory ability in normal pressure hydrocephalus as compared to Alzheimer's disease and healthy controls. J Neurol Sci. 2017;372: 217-9.

50. Reijs BLR, Ramakers IHGB, Elias-Sonnenschein L, Teunissen CE, Koel-Simmelink M, Tsolaki M, et al. Relation of Odor Identification with Alzheimer's Disease Markers in Cerebrospinal Fluid and Cognition. J Alzheimers Dis. 2017;60(3):1025-34

51. Christensen IT, Larsson EM, Holm IE, Nielsen OBF, Andersen S. Olfactory testing in consecutive patients referred with suspected dementia. BMC Geriatr. 2017;17(1):129

52. Quarmley M, Moberg PJ, Mechanic-Hamilton D, Kabadi S, Arnold SE, Wolk DA, et al. Odor Identification Screening Improves Diagnostic Classification in Incipient Alzheimer's Disease. J Alzheimers Dis. 2017;55(4):1497-507.

53. Murphy C, Gilmore MM, Seery CS, Salmon DP, Lasker BR. Olfactory thresholds are associated with degree of dementia in Alzheimer's disease. Neurobiol Aging. 1990;11(4):465-9.

54. Feldman JI, Murphy C, Davidson TM, Jalowayski AA, Jaime GG.
The Rhinologic Evaluation of Alzheimer's Disease. Laryngoscope. 2009;101(11):1198-202.

55. Nordin S, Monsch AU, Murphy C. Unawareness of smell loss in normal aging and Alzheimer's disease: discrepancy between self-reported and diagnosed smell sensitivity. J Gerontol B Psychol Sci Soc Sci. 1995;50(4):P187-92.

56. Getchell ML, Shah DS, Buch SK, Davis DG, Getchell TV. 3-Nitrotyrosine immunoreactivity in olfactory receptor neurons of patients with Alzheimer's disease: implications for impaired odor sensitivity. Neurobiol Aging. 2003;24(5):663-73.

57. Gilbert PE, Barr PJ, Murphy C. Differences in olfactory and visual memory in patients with pathologically confirmed Alzheimer's disease and the Lewy body variant of Alzheimer's disease. J Int Neuropsychol Soc. 2004;10(6):835-42.

58. Gilbert PE, Murphy C. The effect of the ApoE epsilon4 allele on recognition memory for olfactory and visual stimuli in patients with pathologically confirmed Alzheimer's disease, probable Alzheimer's disease, and healthy elderly controls. J Clin Exp Neuropsychol. 2004;26(6):779-94.

59. Sundermann EE, Gilbert PE, Murphy C. Apolipoprotein E epsilon4 genotype and gender: effects on memory. Am J Geriatr Psychiatry. 2007;15(10):869-78.

60. Hori Y, Matsuda O, Ichikawa S. Olfactory function in elderly people and patients with Alzheimer's disease. Psychogeriatrics. 2015;15(3):179-85.

61. Vyhnalek M, Magerova H, Andel R, Nikolai T, Kadlecova A, Laczo J, et al. Olfactory identification in amnestic and non-amnestic mild cognitive impairment and its neuropsychological correlates. J Neurol Sci. 2015;349(1-2):179-84.

62. Moberg PJ, Pearlson GD, Speedie LJ, Lipsey JR, Strauss ME, Folstein SE. Olfactory recognition: differential impairments in early and late Huntington's and Alzheimer's diseases. J Clin Exp Neuropsychol. 1987;9(6):650-64.

63. Buchsbaum MS, Kesslak JP, Lynch G, Chui H, Wu J, Sicotte N, et al. Temporal and Hippocampal Metabolic Rate During an Olfactory Memory Task Assessed by Positron Emission Tomography in Patients With Dementia of the Alzheimer Type and Controls Preliminary Studies. Arch Gen Psychiatry. 1991;48(9):840-7.

64. Roalf DR, Moberg MJ, Turetsky BI, Brennan L, Kabadi S, Wolk DA, et al. A quantitative meta-analysis of olfactory dysfunction in mild cognitive impairment. J Neurol Neurosurg Psychiatry. 2017;88(3):226-32.

65. Dulay MF, Gesteland RC, Shear PK, Ritchey PN, Frank RA. Assessment of the influence of cognition and cognitive processing speed on three tests of olfaction. J ClinExpNeuropsychol. 2008;30:327-37.

66. Arias E, Heron M, Xu J. United States Life Tables, 2014. Natl Vital Stat Rep. 2017;66(4):1-64.

67. Nitrini R, Caramelli P, Bottino CMC, Damasceno BP, Brucki SMD, Anghinah R. Recomendações do Departamento Científico de Neurologia Cognitiva e do Envelhecimento da Academia Brasileira de Neurologia. Arq Neuropsiquiatr 2005;63(3-A):713-9.

68. Frota NAF, Nitrini R, Damasceno BP, Forlenza O, Dias-Tosta E, Silva $A B$, et al. Critérios para o diagnóstico de doença de Alzheimer. Dement Neuropsychol. 2011;5(Suppl 1):5-10. 